\title{
Boundaries in ground beetle (Coleoptera: Carabidae) and environmental variables at the edges of forest patches with residential developments
}

\author{
Doreen E. Davis ${ }^{1}$, Sara A. Gagné ${ }^{\text {Corresp. } 1}$ \\ ${ }^{1}$ Department of Geography and Earth Sciences, University of North Carolina at Charlotte, Charlotte, North Carolina, United States \\ Corresponding Author: Sara A. Gagné \\ Email address: sgagne@uncc.edu
}

Background. Few studies of edge effects on wildlife objectively identify habitat edges or explore nonlinear responses. In this paper, we build on ground beetle (Coleoptera: Carabidae) research that has begun to address these domains by using triangulation wombling to identify boundaries in beetle community structure and composition at the edges of forest patches with residential developments. We hypothesized that edges are characterized by boundaries in environmental variables that correspond to marked discontinuities in vegetation structure between maintained yards and forest. We expected environmental boundaries to be associated with beetle boundaries.

Methods. We collected beetles and measured environmental variables in $200 \mathrm{~m}$ by $200 \mathrm{~m}$ sampling grids centered at the edges of three forest patches, each with a rural, suburban, or urban context, in Charlotte, North Carolina, USA. We identified boundaries within each grid at two spatial scales and tested their significance and overlap using boundary statistics and overlap statistics, respectively. We complemented boundary delineation with $k$-means clustering.

Results. Boundaries in environmental variables, such as temperature, grass cover, and leaf litter depth, occurred at or near the edges of all three sites, in many cases at both scales. The beetle variables that exhibited the most pronounced boundary structure in relation to edges were total species evenness, generalist abundance, generalist richness, generalist evenness, and Agonum punctiforme abundance. Environmental and beetle boundaries also occurred within forest patches and residential developments, indicating substantial localized spatial variation on either side of edges. Boundaries in beetle and environmental variables that displayed boundary structure at edges significantly overlapped, as did boundaries on either side of edges. The comparison of boundaries and clusters revealed that boundaries formed parts of the borders of patches of similar beetle or environmental condition.

Discussion. We show that edge effects on ground beetle community structure and composition and environmental variation at the intersection of forest patches and residential developments can be described by boundaries and that these boundaries overlap in space. However, our results also highlight the complexity of edge effects in our system: environmental boundaries were located at or near edges whereas beetle boundaries related to edges could be spatially disjunct from them; boundaries incompletely delineated edges such that only parts of edges were well-described by sharp transitions in beetle and/or environmental variables; and the occurrence of boundaries related to edges was apparently influenced by individual property management practices, site-specific characteristics such as development geometry, and spatial scale. 
1 Boundaries in ground beetle (Coleoptera: Carabidae) and environmental variables at the

2 edges of forest patches with residential developments

3 Doreen E. Davis and Sara A. Gagné*

4 Department of Geography and Earth Sciences, University of North Carolina at Charlotte, 9201

5 University City Blvd., Charlotte, North Carolina 28223 USA

$6{ }^{*}$ Corresponding author. Email: sgagne@uncc.edu 


\section{Abstract}

8 Background. Few studies of edge effects on wildlife objectively identify habitat edges or explore

9 non-linear responses. In this paper, we build on ground beetle (Coleoptera: Carabidae) research

10 that has begun to address these domains by using triangulation wombling to identify boundaries

11 in beetle community structure and composition at the edges of forest patches with residential

12 developments. We hypothesized that edges are characterized by boundaries in environmental

13 variables that correspond to marked discontinuities in vegetation structure between maintained

14 yards and forest. We expected environmental boundaries to be associated with beetle boundaries.

15 Methods. We collected beetles and measured environmental variables in $200 \mathrm{~m}$ by $200 \mathrm{~m}$

16 sampling grids centered at the edges of three forest patches, each with a rural, suburban, or urban

17 context, in Charlotte, North Carolina, USA. We identified boundaries within each grid at two

18 spatial scales and tested their significance and overlap using boundary statistics and overlap

19 statistics, respectively. We complemented boundary delineation with $k$-means clustering.

20 Results. Boundaries in environmental variables, such as temperature, grass cover, and leaf litter

21 depth, occurred at or near the edges of all three sites, in many cases at both scales. The beetle

22 variables that exhibited the most pronounced boundary structure in relation to edges were total

23 species evenness, generalist abundance, generalist richness, generalist evenness, and Agonum

24 punctiforme abundance. Environmental and beetle boundaries also occurred within forest patches

25 and residential developments, indicating substantial localized spatial variation on either side of

26 edges. Boundaries in beetle and environmental variables that displayed boundary structure at

27 edges significantly overlapped, as did boundaries on either side of edges. The comparison of

28 boundaries and clusters revealed that boundaries formed parts of the borders of patches of similar

29 beetle or environmental condition.

30 Discussion. We show that edge effects on ground beetle community structure and composition

31 and environmental variation at the intersection of forest patches and residential developments can 
32 be described by boundaries and that these boundaries overlap in space. However, our results also

33 highlight the complexity of edge effects in our system: environmental boundaries were located at

34 or near edges whereas beetle boundaries related to edges could be spatially disjunct from them;

35 boundaries incompletely delineated edges such that only parts of edges were well-described by

36 sharp transitions in beetle and/or environmental variables; and the occurrence of boundaries

37 related to edges was apparently influenced by individual property management practices, site-

38 specific characteristics such as development geometry, and spatial scale.

\section{Introduction}

40 Urbanization results in the loss and fragmentation of habitat (Bradley 1995). Habitat fragments,

41 such as forest patches, in developed landscapes are typically small and irregularly-shaped (Gagné

42 2013). Thus, forests in landscapes undergoing urbanization become increasingly dominated by

43 edge habitat, which exhibits markedly altered environmental conditions that may significantly

44 influence the distribution of organisms, such as ground beetles (Coleoptera: Carabidae) (Murcia

45 1995).

46 Ground beetle species richness, abundance, and functional and phylogenetic diversity at

47 the edges of forest patches are higher than (Magura 2002, Magura 2017) or similar to (Heliölä et

48 al. 2001, Magura et al. 2017) that in patch interiors. With increasing distance from the edge into a

49 forest patch, the abundance and species richness of forest specialists increase, the abundance and

50 species richness of open-habitat specialists decrease, and the abundances of generalist species

51 show both responses (Gaublomme et al. 2008, Boetzl et al. 2016).

52 Magura (2002) and Gaublomme et al. (2008) have advanced our understanding of forest

53 edge effects on ground beetles by attempting to objectively identify edge and interior habitats and

54 by testing for non-linear responses to distance from the edge, respectively - important approaches

55 that have received relatively little attention by researchers in the field (Ries et al. 2004). Using a 
56 two-pane moving window applied to transect data, Magura (2002) defined the edges between

57 forest interior, forest edge, and grass habitats as the locations where community dissimilarity

58 between adjacent sampling locations was at a maximum. Ground beetle species richness differed

59 significantly among the three so-defined habitats. Gaublomme et al. (2008) found that the

60 abundances of individual ground beetle species exhibited steep increases or decreases,

61 accompanied by little change and/or a reversal in the direction of change, in response to distance

62 from the forest edge.

63 In this paper, we build on these advances by using triangulation wombling to identify

64 boundaries in ground beetle community structure and composition at the developed edges of

65 forest patches. Triangulation wombling is a spatial partitioning technique that identifies locations

66 in sampling grids where variables of interest, such as ground beetle abundance, change

67 dramatically, i.e., boundaries (Fortin and Dale 2005). Using this method, we sought to address

68 two research questions: (1) what are the spatial patterns of ground beetle community structure

69 and composition and environmental variation at the intersection of forest patches and residential

70 developments?, and (2) are the patterns of ground beetle community structure and composition

71 and environmental variation related? We hypothesized that edges between forest patches and

72 residential developments are characterized by boundaries in environmental variables that

73 correspond to marked discontinuities in vegetation structure between maintained yards and forest.

74 Edges between natural and developed land covers are typically characterized by high contrast in

75 vegetation structure (Bennett 2003). For example, large abrupt changes in the covers of bare

76 ground, grass, leaf litter, and projective foliage occur at the edges of forests and residential

77 developments in Australia (Villaseñor et al. 2016). We expected environmental boundaries to be

78 associated with boundaries in beetle community structure and composition. High contrast edges

79 are hypothesized to exhibit large magnitudes of edge influence due to reduced edge permeability

80 (Ries et al. 2004, Harper et al. 2005). Ground beetles have previously been shown to exhibit 
81 sharp changes in community composition at edges (Magura 2002, Gaublomme et al. 2008, Leslie

82 et al. 2014) and less movement across high contrast than low contrast edges (Collinge and Palmer 83 2002).

\section{Materials \& Methods}

85 Study area and site selection

86 We selected three forest patch edges with residential developments in the city of Charlotte,

87 Mecklenburg County, North Carolina, USA, part of one of the most rapidly-growing metropolitan

88 regions in the country (Kotkin and Cox 2011) (Fig. 1). Hereafter, we use the term "edge" to refer

89 to the property lines between the County-owned forest patches and privately-owned residential

90 developments in our study that approximately corresponded to differences in vegetation

91 management practices. This is in contrast to the term "boundary", which we use in a technical

92 sense to refer to areas of major change within ground beetle trapping grids. We use the term

93 "site" to refer to the area of each trapping grid.

94 We restricted our forest patch selection to upland hardwood forest of as similar a size as

95 possible $\left(0.22-0.63 \mathrm{~km}^{2}\right)$ and similar fractal dimension, an index of patch shape (McGarigal et al.

96 2012) (Table 1). All forest patches had a straight, southward-facing edge with a residential

97 development composed of single-family homes (Fig. 1). Each site contained a similar number of

98 houses (Table 1).

99 We also selected forest patches to represent a range of contexts in our study area. For each

100 patch, we quantified intensity of urbanization using a building density raster calculated from 2011

101 Mecklenburg County tax parcel data and a $1 \mathrm{~km}$-radius moving window, the size of which

102 approximates the dispersal range of ground beetles (Baars 1979). A rural, suburban, or urban

103 context was attributed to a patch according to the values of the majority of the cells abutting the 104 patch (Table 1). 
105 Ground beetle trapping

106 Pitfall traps were installed $25 \mathrm{~m}$ apart to minimize local depletion of ground beetles (Digweed et

107 al. 1995) in approximately 9 trap 9 trap grids centered at forest/residential edges, for a total

108 sampling area of $62,500 \mathrm{~m}^{2}$ per site (Fig. 1). Local adjustments to trap location (average inter-trap

109 distance was approximately $20 \mathrm{~m}$ ) and a reduction in trap number (minimum of 75 traps/site)

110 were necessary to accommodate landowner consent and the presence of impervious surfaces

111 (Table 1).

112 Each trap consisted of one inner and one outer white cup (Spence and Niemelä 1994)

113 placed flush with the ground surface, with an opening diameter of $90 \mathrm{~mm}$ and a depth of $120 \mathrm{~mm}$.

$114100 \mathrm{ml}$ of undiluted propylene glycol and a drop of dish soap were used as preservative and

115 surfactant, respectively, and a white roof was placed $25 \mathrm{~mm}$ over the trap to prevent the intrusion

116 of rain and debris. We collected trap contents 11 times, approximately every two weeks between

117 April 4 and August 5, 2011. We identified ground beetles to species using Lindroth (1961-69),

118 Ciegler (2000), and Bousquet (2010). Nomenclature corresponds to that in Bousquet (2012).

119 Measurement of environmental variables

120 We measured environmental variables identified as important predictors of ground beetle species

121 richness and abundance (Lövei \& Sunderland 1996, Magura 2002, Lassau et al. 2005, Magura et

122 al. 2005) at each trap location. In May 2012, we used a densitometer (Geographic Resource

123 Solutions, Arcata, CA, USA) to estimate the cover of canopy, trees (diameter at breast height

$124(\mathrm{DBH}) \geq 2.5 \mathrm{~cm})$, shrubs $(\mathrm{DBH}<2.5 \mathrm{~cm})$, woody vines, non-creeping and creeping forbs,

125 grasses, mosses, human-made mulch, coarse woody debris, bare ground, rock, and impervious

126 surfaces. We recorded densitometer readings at $0.92 \mathrm{~m}$ intervals along two $3.66 \mathrm{~m}$ perpendicular

127 transects centered at each trap location. Transect orientation was determined randomly using a

128 compass. We measured vegetation and ground cover at a height of $1.5 \mathrm{~m}$, with the densitometer

129 pointed upwards for canopy cover and downwards for all other variables. We also recorded leaf 
130 litter depth at the same intervals along transects. We estimated the microrelief and slope of the

131 area encompassed by transects by ranking the surface as very even, slightly even, uneven, very

132 uneven, or extremely uneven and of no, weak, moderate, or steep slope, respectively (St-Louis et

133 al. 2004).

134 In June 2013, we measured surface temperature and relative humidity using LogTag

135 HAXO-8 data loggers (MicroDAQ.com, Contoocook, NH, USA) placed on the ground at each

136 trap location. We recorded data every minute from 12-3 pm on June 21 at the rural site and on

137 June 20 at the suburban site, and from 1-3 pm on June 14 at the urban site. All time periods had

138 similar weather conditions with air temperatures of $25.6-28.3^{\circ} \mathrm{C}$, atmospheric pressures of 101.3 -

$139102.4 \mathrm{kPa}$, and partly cloudy skies.

140 Analyses

141 We used triangulation wombling to identify boundaries in ground beetle community structure and

142 composition and environmental variation at each site (Fortin and Dale 2005). In doing so, we

143 assumed that underlying environmental gradients encompassed site areas, a reasonable

144 assumption given the relatively small size of sites. We identified boundaries at two spatial scales,

145 the original sampling scale and a larger scale represented by the centroids of trios of adjacent trap

146 locations (average inter-trap distance was approximately $36 \mathrm{~m}$ ), to account for the scale-

147 dependency of boundary occurrence (Fortin and Dale 2005). First, we grouped data points (trap

148 locations at the small scale, centroids at the large scale) into triangles using the Delaunay

149 triangulation algorithm (Fig. S1). Second, we calculated the slope, or rate of change, of a plane fit

150 to the values of a variable of interest observed at each triangle's vertices using the first partial

151 derivative of the variable in two linear dimensions. We also calculated the orientation, or angle of

152 change, of the plane. Third, rates of change were assigned to the centroids of triangles and were

153 deemed candidate boundary elements if they fell within the top quintile of the distribution of rates

154 of change at the site (Fortin and Dale 2005). Finally, candidate boundary elements were 
155 connected if they met three criteria: they were adjacent to one another; their orientations differed

156 by $\leq 90^{\circ}$, i.e., they were oriented in roughly the same direction; and the angles between their

157 orientations and the connecting line was $\geq 30^{\circ}$ (so that the connecting line differentiated between

158 areas with very different values of the variable). For simplicity, we refer to connected candidate

159 boundary elements as boundaries and unconnected candidate boundary elements as singletons in

160 the remainder of the paper.

161 We used BoundarySeer, version 1.5.3 (BioMedware 2015) to delineate boundaries in the

162 species richnesses, evennesses, and abundances of all beetles, forest specialists, open-habitat

163 specialists, and generalists; the abundance matrix of each of these groups; and the abundances of

164 individual species. We classified species as forest specialists if they were only associated with

165 forest habitats, as open-habitat specialists if they were only associated with open habitats, and as

166 generalists if they were reported to occur in both habitat types according to the accounts in

167 Larochelle and Larivière (2003) (Table S1). Species richnesses were cumulative numbers of

168 species and abundances were sums of individuals collected over the trapping period, divided by

169 the number of successful collections to eliminate the effect of trap disturbance on catch data. We

170 used corrected species richnesses and abundances to calculate species evennesses using the

171 Berger-Parker index (Berger and Parker 1970), with the exception of forest and open-habitat

172 specialists that were collected at too few traps at each site. Abundance matrices were analyzed in

173 their original form and with species abundances weighted by the inverse of the species'

174 proportion of total abundance at the site to favor rare species. We also delineated boundaries in

175 standardized environmental variables, both singly and as a matrix.

176 We determined the significance of the boundary structure exhibited by each variable at

177 each site and scale using boundary statistics (Oden et al. 1993). The significance $(p<0.10)$ of

178 statistics was assessed by randomizing rates of change 9,999 times assuming complete spatial

179 randomness (Oden et al. 1993). We chose to use a significance threshold greater than 0.05 to 
180 lessen Type II error given the novelty of our study objective. Also, Fortin and Dale (2005)

181 suggest that statistics with $p>0.05$, in combination with map observations, can be interpreted in

182 order to understand boundary patterns. We also calculated overlap statistics for pairs of beetle and

183 environmental variables, each with one or more significant boundary statistics, in order to assess

184 the degree of spatial coincidence between beetle and environmental boundaries and singletons

185 (Fortin et al. 1996, Jacquez 1995). We determined the significance of overlap statistics in the

186 same manner as for boundary statistics but by randomizing only the beetle variable in a pair

187 (BioMedware 2015). We considered the boundaries and singletons of a beetle-environmental

188 variable pair to exhibit overlap if they occurred significantly close to one another and/or at a

189 significantly large number of the same locations.

190 Fortin and Dale (2005) recommend complementing boundary detection with clustering to

191 aid in the interpretation of results. We applied the $k$-means clustering algorithm to variables with

192 one or more significant boundary statistics that displayed boundaries and/or singletons at, near, or

193 parallel to the edge at each site and scale using the cascadeKM function in the vegan 2.4-1

194 package of $\mathrm{R}$, version 3.3.1 (R Core Team 2016). We clustered standardized variables into 2-10

195 groups at the small scale and 2-5 groups at the large scale to explore the spatial coincidence of

196 clusters, boundaries and singletons. We did not cluster single abundance or species richness

197 variables because the Euclidean distance measure used in the $k$-means algorithm is not

198 appropriate for such data and we were unaware of a transformation to overcome this limitation

199 that is applicable to individual variables.

\section{Results}

201 Across all sites, we collected 350 ground beetles per successful trapping period from 26 genera

202 and 50 species (Table S1). The suburban site had the greatest number of individuals per trapping

203 period (132) and species (40), followed by the rural site (115 individuals per trapping period from 
20431 species) and the urban site (103 individuals per trapping period from 31 species). Most beetle

205 individuals (84\%) and species (62\%) were generalists. Forest specialists represented $0.6 \%$ of

206 individuals and $16 \%$ of species whereas open-habitat specialists represented $10 \%$ of individuals

207 and $14 \%$ of species.

208 Two-thirds of environmental variables and one quarter of beetle variables had significant

209 boundary statistics at the rural site at the small spatial scale (Table S2, Fig. 2, Figs. S2-S14).

210 Relatively long boundaries in forb, grass (Fig. 2A), and vine cover occurred along part of the

211 edge at the site, overlapping at the back of the central house's lot. The remainder of

212 environmental variables displayed boundaries in other areas of the site that coincided with major

213 structural change, such as in canopy cover (Fig. 2B). Beetle variables generally exhibited

214 localized spatial variation that did not follow the edge (e.g., Fig. 2C), with the exception of total

215 species evenness, which displayed two short boundaries along the edge.

216 At the rural site at the large spatial scale, about one third of environmental variables and

217 one third of beetle variables were characterized by significant boundary statistics (Table S3, Fig.

218 2, Figs. S15-S30). Linear boundaries in temperature and humidity (Fig. 2D) occurred near the

219 edge at the same location that boundaries in forb, grass, and vine covers did at the small scale.

220 Total species evenness and generalist evenness (Fig. 2E) exhibited relatively long linear

221 boundaries parallel to but at a distance into the forest from the edge. Generalist abundance

222 displayed a similar pattern on the developed side of the site (Fig. 2F). All other beetle and

223 environmental variables exhibited localized spatial variation in areas other than at the edge.

224 One or more boundary statistics was significant for about half of environmental variables

225 and one fifth of beetle variables at the suburban site at the small scale (Table S4, Fig. 3, Figs.

226 S31-S45). The matrix of all environmental variables exhibited a relatively long linear boundary

227 along part of the edge (Fig. 3A) where leaf litter depth, grass cover, shrub cover, and total species

228 evenness also displayed short boundaries. These and the remaining variables displayed 
229 boundaries and singletons in other areas of the site as well. In particular, boundaries and

230 singletons in all environmental variables, leaf litter depth, the covers of forb (Fig. 3B), grass,

231 shrub, and creeping forb, total species evenness, generalist evenness, and the abundances of

232 Poecilus lucublandus lucublandus (Fig. 3C) and Pterostichus sculptus occurred along a stream in

233 the forested part of the site.

234 Boundaries and singletons in P. lucublandus lucublandus abundance (Fig. 3D), as well as

235 in vine cover and leaf litter depth (Fig. 3E), also occurred along the stream at the suburban site at

236 the large scale, at which one fifth of environmental variables and one third of beetle variables had

237 significant boundary statistics (Table S5, Figs. S46-S60). No boundaries in any variable occurred

238 along the edge. Most beetle variables instead displayed very localized spatial variation in other

239 areas of the site (e.g., Fig. 3F).

240 Eighty-five percent of environmental and $40 \%$ of beetle variables had significant

241 boundary statistics at the urban site at the small scale (Table S6, Fig. 4, Figs. S61-S84). Several

242 environmental variables exhibited boundaries along part of the edge of the site, including leaf

243 litter depth (Fig. 4A), slope (Fig. 4B), and the covers of canopy, shrub, and vine. With the

244 exception of leaf litter depth, slope, and shrub cover, these boundaries were restricted to the

245 backyard of the same property. Boundaries in environmental variables, such as canopy cover and

246 impervious surface cover, also delineated structural change in other areas of the site. Several

247 beetle variables, including total abundance and evenness, generalist abundance and evenness,

248 forest specialist abundance and richness, and the abundances of Agonum punctiforme and

249 Scarites subterraneus exhibited a few short boundaries and/or singletons along the edge of the

250 site, mostly at two distinct locations. Of these, the abundance of $A$. punctiforme displayed the

251 most boundaries and singletons (Fig. 4C). Boundaries and singletons in all beetle variables

252 occurred in other areas of the site as well. 
254 beetle variables were characterized by significant boundary statistics (Table S7, Fig. 4, Figs. S85-

255 S92). Microrelief, leaf litter depth, and generalist species richness exhibited boundaries along or

256 near parts of the edge (Figs. 4D-F) and in other areas of the site, as did the remaining variables.

257 One of the boundaries in leaf litter depth was associated with the backyard of the property where 258 several environmental boundaries occurred at the small scale.

259 Boundaries and singletons in beetle and environmental variables that displayed boundary

260 structure at edges significantly overlapped (Tables S8-S13). At the small scale, boundaries and

261 singletons in total species evenness overlapped those in vine cover at the rural site, those in leaf

262 litter depth and the covers of grass and shrub at the suburban site, and those in slope, leaf litter

263 depth, and vine cover at the urban site. Generalist abundance boundaries and singletons spatially

264 co-occurred with those in temperature at the rural site at the large scale, and generalist evenness

265 boundaries and singletons overlapped those in the covers of canopy, shrub, and vine at the urban

266 site at the small scale. At the urban site at the large scale, boundaries in generalist richness were

267 spatially associated with those in leaf litter depth. Finally, at the urban site at the small scale,

268 boundaries and singletons in forest species abundance and richness significantly overlapped those

269 in leaf litter depth and shrub cover, and boundaries and singletons in the abundances of $A$.

270 punctiforme and $S$. subterraneus spatially co-occurred with those in canopy cover.

271 Many other pairs of beetle and environmental boundaries and singletons exhibited

272 significant spatial overlap (Tables S8-S13). For example, at the rural site at the small scale,

273 boundaries in open-habitat abundance co-occurred with those in temperature, the covers of

274 canopy, forb, and grass, and all environmental variables. At the suburban site at the small scale,

275 boundaries and singletons in the abundances of P. lucublandus lucublandus and P. sculptus

276 overlapped those in creeping forb and shrub covers. P. lucublandus lucublandus boundaries and

277 singletons also overlapped boundaries and singletons in forb and grass covers. 
279 boundaries and singletons in beetle and environmental variables (Fig. 5, Figs. S93-S108). In

280 general, boundaries and singletons bordered parts of cluster patches, as was the case for the red

281 cluster of grass cover at the rural site at the small scale (Fig. 5A), the blue and white clusters of

282 generalist evenness at the rural site at the large scale (Fig. 5B), the blue and white clusters of

283 grass cover (Fig. 5C) and total species evenness (Fig. 5D) at the suburban site at the small scale,

284 and the blue and white clusters of leaf litter depth at the urban site at the large scale (Fig. 5E). In

285 a few instances, boundaries and singletons corresponded to the borders between patches of some

286 clusters at a site, e.g., the green cluster in leaf litter depth at the urban site at the small scale (Fig.

287 5F), but not others, e.g., the white cluster at the same site and scale. The spatial patterns of

288 clusters at sites fell into two broad categories, one highlighting the difference between the

289 forested and developed sides of sites (Figs. 5A, B, E, and F) and the other the localized, patchy

290 nature of a variable's distribution throughout a site (Figs. 5C and D).

\section{Discussion}

292 Our results demonstrate that the edges of forest patches with residential developments are

293 characterized by boundaries in ground beetle community structure and composition and

294 environmental variation. Boundary structure at edges appeared to be influenced by site-specific

295 factors and individual property management practices. Overlapping boundaries in ground beetle

296 community structure and composition and environmental variation also occurred within forest

297 patches and residential developments, indicating substantial localized spatial variation on either

298 side of edges. These results in combination with those of our clustering analyses suggest that the

299 spatial patterns of ground beetle community structure and composition and environmental

300 variation at the intersection of forest patches and residential developments are described by

301 locations of sharp transition and more gradual gradients. 
303 edges were total species evenness, generalist abundance, and generalist evenness at the rural site

304 at the large spatial scale, generalist species richness at the urban site at the large scale, and $A$.

305 punctiforme abundance at the urban site at the small scale. The long linear boundary in total

306 evenness set back in the forest at the rural site, and in generalist evenness at the same location,

307 likely reflect the spillover of generalist species from the developed side of the site, a pattern that

308 has been demonstrated at grassland edges with cropland (Schneider et al. 2016) and at railway

309 verges bordered by grassland or forest (Prass et al. 2017). Based on the significant overlap of

310 boundaries and singletons in total evenness and vine cover at the rural site at the small scale, we

311 posit that the presence of continuous vine cover in the forest near the edge facilitated the spillover

312 of generalist species, possibly because habitat conditions associated with vine cover were similar

313 to those on the developed side of the site and/or because vine cover posed a significant barrier to

314 the movement of forest specialist species (Magura 2017).

315 The location of total and generalist evenness boundaries at the rural site illustrates that

316 major changes in community structure may not occur at the human-defined edge of a patch.

317 Instead, processes associated with the human-defined edge may alter habitat conditions over a

318 wider area, resulting in an organism-perceived 'edge' spatially disjunct from the human-perceived

319 one. This spatial incongruity was also apparent in the location of the boundary in generalist

320 abundance on the developed side of the site, which significantly overlapped boundaries in

321 temperature. Temperature is positively associated with generalist beetle species activity

322 (Chiverton 1988).

323 Boundaries and singletons in generalist richness and A. punctiforme abundance at the

324 urban site did coincide with the edge of the forest patch. A. punctiforme is a generalist species

325 that is common in disturbed habitats, including those characteristic of residential development

326 (Larochelle and Larivière 2003). Many short boundaries and singletons in the abundance of the 
327 species occurred throughout the developed side of the urban site at the small scale, where they

328 significantly overlapped those in canopy cover, including at the edge. The occurrence of several 329 generalist species nearly exclusively on the developed side of the site, including A. punctiforme

330 and $S$. subterraneus that also exhibited boundaries and singletons at the edge at the small scale,

331 may underlie the relatively long linear boundary in generalist richness at the edge at the large 332 scale.

333 Ground beetle and environmental boundary patterns associated with edges appeared to be 334 mediated by individual property management practices, development geometry, and site context.

335 At all three sites, the backyards of single properties abutting edges were the locations of linear

336 boundaries in multiple environmental variables, in some cases at both scales. For example, one

337 property's backyard at the urban site was delineated by boundaries in slope, leaf litter depth, and

338 the covers of canopy, shrub, and vine at the small scale and leaf litter depth at the large scale.

339 Thus, it seems reasonable to suggest that variation in yard maintenance practices, perhaps

340 associated with local environmental constraints such as steep slopes, may contribute to the

341 location of environmental boundaries at edges. Adding to the influence of this variation is the

342 possible effect of development geometry. The suburban site differed from the other two sites in

343 that roads, and a treed corridor between them, were oriented approximately perpendicular to the

344 forest patch edge rather than parallel to it as at the other sites. This geometry effectively limited

345 the number of backyards abutting the edge and consequently the likelihood of abrupt changes in

346 environmental variation and ground beetle community structure and composition at the edge.

347 Accordingly, the suburban site exhibited the fewest boundaries and singletons associated with the

348 edge at either scale of any site. Finally and notwithstanding the potential effects of management

349 practices and development geometry, we think it possible that site context, in the form of patch

350 area and surrounding building density, may have influenced boundary structure at edges. The

351 rural site was located at the edge of the largest forest patch and exhibited the longest linear 
352 boundaries in environmental and ground beetle variables related to the edge at both scales of all

353 three sites. One would expect the strongest edge effects to occur in the largest patch (Soga et al.

354 2013) surrounded by the least disturbed context (Gaublomme et al. 2008, Jung and Lee 2016).

355 Ground beetles exhibited substantial boundary structure that overlapped environmental

356 boundaries and singletons not just at edges, but throughout sites. For example, boundaries and

357 singletons in open-habitat abundance at the rural site at the small scale co-occurred with those in

358 temperature and the covers of canopy, grass, and forb on the developed side of the site. Also, the

359 abundance of P. lucublandus lucublandus displayed boundaries and singletons along the stream

360 in the forested half of the suburban site at the small scale that overlapped boundaries and

361 singletons in the covers of grass, forb, creeping forb, and shrub at the same location. These

362 results highlight not only associations between ground beetle abundance and microclimatic and

363 cover variables that have been reported in the literature (Magura et al. 2004, Bergmann et al.

364 2012), but also illustrate the localized occurrence of ground beetles in response to environmental

365 heterogeneity.

366 The superposition of boundaries, singletons, and clusters revealed that boundaries and

367 singletons formed parts of the borders of patches of similar ground beetle or environmental

368 condition, including those that differentiated between the forested and developed sides of sites.

369 The fact that boundaries and singletons only bordered parts of patches demonstrates that edge

370 effects at our sites manifested as abrupt transition in some places, indicated by the presence of

371 boundaries and singletons, and more gradual change in others, indicated by their absence. The

372 existence of this variation in the form of edge effects at our sites is not surprising given the high

373 degree of spatial heterogeneity characteristic of urban areas. Our comparison of the results of

374 boundary and cluster analyses supports the idea that the approaches together describe the

375 locations and shapes of patches in an area and the form of borders among them, as also

376 demonstrated by Fortin and Drapeau (1995). 


\section{Conclusions}

378 We show that edge effects on ground beetle community structure and composition and

379 environmental variation at the intersection of forest patches and residential developments can be

380 described by boundaries and that these boundaries often overlap in space. We found relatively

381 long boundaries in multiple environmental variables, such as grass cover and leaf litter depth, and

382 beetle variables, such as total species evenness, associated with edges. However, our results also

383 highlight the complexity of edge effects in our system: environmental boundaries were located at

384 or near edges whereas beetle boundaries related to edges could be spatially disjunct from them;

385 boundaries incompletely delineated edges such that only parts of edges were well-described by

386 sharp transitions in beetle and/or environmental variables; and the occurrence of boundaries

387 related to edges was apparently influenced by individual property management practices, site-

388 specific characteristics such as development geometry, and spatial scale. Also, boundaries

389 occurred throughout site areas, revealing substantial localized spatial variation in environmental

390 conditions and ground beetle community structure and composition within $100 \mathrm{~m}$ either side of

391 edges. We hope that our identification of boundaries and the complexity that it revealed are

392 fodder for future investigations of organismal patterns at heterogeneous urban edges.

\section{Acknowledgements}

394 We very much thank Sandra Clinton, William Garcia, and two anonymous reviewers for their

395 helpful feedback on an earlier version of this manuscript. We are also indebted to Luke Browder,

396 Rufus McLean, and Jacob Todd who helped to collect field data, to Kelly Brawn for help with all

397 things GIS, and to Janet Ciegler who confirmed our beetle identifications. Very special thanks are

398 due to the landowners at our sites, including the Mecklenburg County Division of Nature

399 Preserves and Natural Resources, whose cooperation made this research possible. 
400

401

402

403

404

405

406

407

408

409

410

411

412

413

414

415

416

417

418

419

420

421

422

423

\section{References}

Baars, M. A. 1979. Patterns of movement of radioactive carabid beetles. Oecologia 44:125-140.

Bennett, A. F. 2003. Linkages in the landscape: the role of corridors and connectivity in wildlife conservation. IUCN, Gland, Switzerland and Cambridge, UK.

Berger, W. H., and F. L. Parker. 1970. Diversity of planktonic foraminifera in deep-sea sediments. Science 168:1345-1347.

Bergmann, D. J., D. Brandenburg, S. Petit, and M. Gabel. 2012. Habitat preferences of ground beetle (Coleoptera: Carabidae) species in the northern Black Hills of South Dakota. Environmental Entomology 41:1069-1076.

BioMedware. 2015. BoundarySeer: software for the detection and analysis of geographic boundaries. BioMedware, Ann Arbor, Michigan, USA.

Boetzl, F. A., G. Schneider, and J. Krauss. 2016. Asymmetric carabid beetle spillover between calcareous grasslands and coniferous forests. Journal of Insect Conservation 20:49-57.

Bousquet, Y. 2010. Illustrated identification guide to adults and larvae of northeastern North American ground beetles (Coleoptera: Carabidae). Pensoft Publishers, Sophia, Bulgaria.

Bousquet, Y. 2012. Catalogue of the Geadephaga (Coleoptera, Adephaga) of America, north of Mexico. Zookeys 245:1-1722.

Bradley, G. 1995. Urban forest landscapes: integrating multidisciplinary perspectives. Pages 311 in G. Bradley, editor. Urban forest landscapes: integrating multidisciplinary perspectives. University of Washington Press, Seattle, Washington, USA.

Chiverton, P. A. 1988. Searching behaviour and cereal aphid consumption by Bembidion lampros and Pterostichus cupreus, in relation to temperature and prey density. Entomologia Experimentalis et Applicata 47:173-182.

Ciegler, J. C. 2000. Ground beetles and wrinkled bark beetles of South Carolina (Coleoptera: 
424

425

426 Collinge, S. K., and T. M. Palmer. 2002. The influences of patch shape and boundary contrast on 427
Geadephaga: Carabidae and Rhysodidae). Clemson University, Clemson, South Carolina, USA. 656.

Digweed, S. C., C. R. Currie, H. A. Cárcamo, and J. R. Spence. 1995. Digging out the 'diggingin effect' of pitfall traps: influences of depletion and disturbance on catches of ground beetles (Coleoptera: Carabidae). Pedobiologia 39:561-576.

Fortin, M.-J., and M. R. T. Dale. 2005. Spatial analysis: a guide for ecologists. Cambridge University Press, Cambridge, UK.

Fortin, M.-J., and P. Drapeau. 1995. Delineation of ecological boundaries: comparison of approaches and significance tests. Oikos 72:323-332.

Fortin, M.-J., P. Drapeau, and G. M. Jacquez. 1996. Quantification of the spatial co-occurrences of ecological boundaries. Oikos 77:51-60.

Gagné, S. A. 2013. The distinguishing features of the study of the ecology of urban landscapes. Geography Compass 7:266-286.

Gaublomme, E., F. Hendrickx, H. Dhuyvetter, and K. Desender. 2008. The effects of forest patch size and matrix type on changes in carabid beetle assemblages in an urbanized landscape. Biological Conservation 141:2585-2596.

Harper, K. A., S. E. MacDonald, P. J. Burton, J. Chen, K. D. Brosofske, S. C. Saunders, E. S. Euskirchen, D. Roberts, M. S. Jaiteh, and P.-A. Esseen. 2005. Edge influence on forest structure and composition in fragmented landscapes. $\quad$ Conservation Biology 19:768-782.

Heliölä, J., M. Koivula, and J. Niemelä. 2001. Distribution of carabid beetles (Coleoptera: Carabidae) across a boreal forest-clearcut ecotone. Conservation Biology 15:370-377. 
449 Jacquez, G. M. 1995. The map comparison problem: tests for the overlap of geographical $450 \quad$ boundaries. Statistics in Medicine 14:2343-2361.

451 Jung, J.-K., and J.-H. Lee. 2016. Forest-farm edge effects on communities of ground beetles 452 (Coleoptera: Carabidae) under different landscape structures. Ecological Research $453 \quad 31: 799-810$.

454 Kotkin, J., and W. Cox. 2011, April 15. The Census' fastest-growing cities of the decade. Forbes. 455 Retrieved from https://www.forbes.com/sites/joelkotkin/2011/04/15/the-census-fastest456 growing-cities-of-the-decade/\#4ed341894564

457 Larochelle, A., and M.-C. Larivière. 2003. A natural history of the ground-beetles (Coleoptera: 458 Carabidae) of America north of Mexico. Pensoft Publishers, Sophia, Bulgaria.

459 Lassau, S. A., D. F. Hochuli, G. Cassis, and C. A. M. Reid. 2005. Effects of habitat complexity 460 on forest beetle diversity: do functional groups respond consistently? Diversity and $461 \quad$ Distributions 11:73-82.

462 Leslie, T. W., D. J. Biddinger, J. R. Rohr, A. G. Hulting, D. A. Mortensen, and S. J. Fleischer. 463 2014. Examining shifts in Carabidae assemblages across a forest-agriculture ecotone. $464 \quad$ Environmental Entomology 43:18-28.

465 Lindroth, C. H. 1961-69. The ground-beetles of Canada and Alaska. Opuscula Entomologica 14661192.

467 Lövei, G. L., and K. D. Sunderland. 1996. Ecology and behavior of ground beetles (Coleoptera: 468 Carabidae). Annual Review of Entomology 41:231-256.

469 Magura, T. 2002. Carabids and forest edge: spatial pattern and edge effect. Forest Ecology and $470 \quad$ Management 157:23-37.

471 Magura, T. 2017. Ignoring functional and phylogenetic features masks the edge influence on 472 ground beetle diversity across forest-grassland gradient. Forest Ecology and Management 473 $384: 371-377$. 
474 Magura, T., G. L. Lö vei, and B. Tóthmérész. 2017. Edge responses are different in edges under

475 natural versus anthropogenic influence: a meta-analysis using ground beetles. Ecology

$476 \quad$ and Evolution 7:1009-1017.

477 Magura, T., B. Tóthmérész, and Z. Elek. 2005. Impacts of leaf-litter addition on carabids in a $478 \quad$ conifer plantation. Biodiversity and Conservation 14:475-491.

479 Magura, T., B. Tóthmérész, and T. Molnár. 2004. Changes in carabid beetle assemblages along 480 an urbanization gradient in the city of Debrecen, Hungary. Landscape Ecology 19:747$481 \quad 759$.

482 McGarigal, K., S. A. Cushman, and E. Ene. 2012. FRAGSTATS: spatial pattern analysis 483 program for categorical and continuous maps. University of Massachusetts Amherst, $484 \quad$ Amherst, Massachusetts, USA.

485 Murcia, C. 1995. Edge effects in fragmented forests: implications for conservation. Trends in 486 Ecology and Evolution 10:58-62.

487 Oden, N. L., R. Sokal, M.-J. Fortin, and H. Goebl. 1993. Categorical wombling: detecting 488 regions of significant change in spatially located categorical variables. Geographical $489 \quad$ Analysis 25:315-336.

490 Prass, M., A. Vrezec, H. Setälä, and D. J. Kotze. 2017. The matrix affects carabid beetle 491 assemblages in linear urban ruderal habitats. Urban Ecosystems 20:971-981.

492 R Core Team. 2016. R: a language and environment for statistical computing. R Foundation for 493 Statistical Computing, Vienna, Austria.

494 Ries, L., R. J. Fletcher, J. Battin, and T. D. Sisk. 2004. Ecological responses to habitat edges:

495 mechanisms, models, and variability explained. Annual Review of Ecology, Evolution, 496 and Systematics 35:491-522.

497 Schneider, G., J. Krauss, F. A. Boetzl, M.-A. Fritze, and I. Steffan-Dewenter. 2016. Spillover 

semi-natural grasslands. Oecologia 182:1141-1150.

500 Soga, M., N. Kanno, Y. Yamaura, and S. Koike. 2013. Patch size determines the strength of edge 501 effects on carabid beetle assemblages in urban remnant forests. Journal of Insect 502 Conservation 17:421-428.

503 Spence, J. R., and J. K. Niemelä. 1994. Sampling carabid assemblages with pitfall traps: the 504 madness and the method. The Canadian Entomologist 126:881-894.

505 St-Louis, V., M.-J. Fortin, and A. Desrochers. 2004. Spatial association between forest 506 heterogeneity and breeding territory boundaries of two forest songbirds. Landscape $507 \quad$ Ecology 19:591-601.

508 Villaseñor, N. R., W. Blanchard, and D. B. Lindenmayer. 2016. Decline of forest structural 509 elements across forest-urban interfaces is stronger with high rather than low residential 510 density. Basic and Applied Ecology 17:418-427. 


\section{Table $\mathbf{1}$ (on next page)}

Site characteristics

Characteristics of the studied forest patches and the sites encompassing grids of pitfall traps centered at their edges in Charlotte, North Carolina, USA. All patches were upland hardwood forest. Edges were southward-facing and abutted developments with single-family homes. 
1 Table 1. Characteristics of the studied forest patches and the sites encompassing grids of pitfall

2 traps centered at their edges in Charlotte, North Carolina, USA. All patches were upland

3 hardwood forest. Edges were southward-facing and abutted developments with single-family

4 homes.

\begin{tabular}{llllll}
\hline $\begin{array}{l}\text { Patch context } \\
\left.\text { (buildings } / \mathrm{km}^{2}\right)\end{array}$ & $\begin{array}{l}\text { Patch area } \\
\left(\mathrm{km}^{2}\right)\end{array}$ & $\begin{array}{l}\text { Patch fractal } \\
\text { dimension }\end{array}$ & $\begin{array}{l}\text { Number of single-family } \\
\text { homes in site }\end{array}$ & $\begin{array}{l}\text { Number of pitfall } \\
\text { traps in site }\end{array}$ & $\begin{array}{l}\text { Inter-trap distance } \\
(\mathrm{m} \pm \mathrm{SE})\end{array}$ \\
\hline Rural $(<145)$ & 0.63 & 1.27 & 9 & 75 & $19.8 \pm 9.5$ \\
Suburban & 0.22 & 1.29 & 13 & 77 & $19.5 \pm 9.6$ \\
$(145-1000)$ & & & & 78 & $21.3 \pm 10.8$ \\
Urban $(>1000)$ & 0.31 & 1.26 & 15 & & 78 \\
\hline
\end{tabular}

5 


\section{Figure 1}

Map of sites

The locations of study sites consisting of grids of pitfall traps for ground beetles spanning the edges of forest patches with residential developments in Mecklenburg County, North

Carolina, USA. Edges are indicated by black lines and correspond to the property lines between County-owned forest and private development. Each site was at the edge of a patch surrounded by a rural, suburban, or urban context. Aerial imagery courtesy of Mecklenburg County.

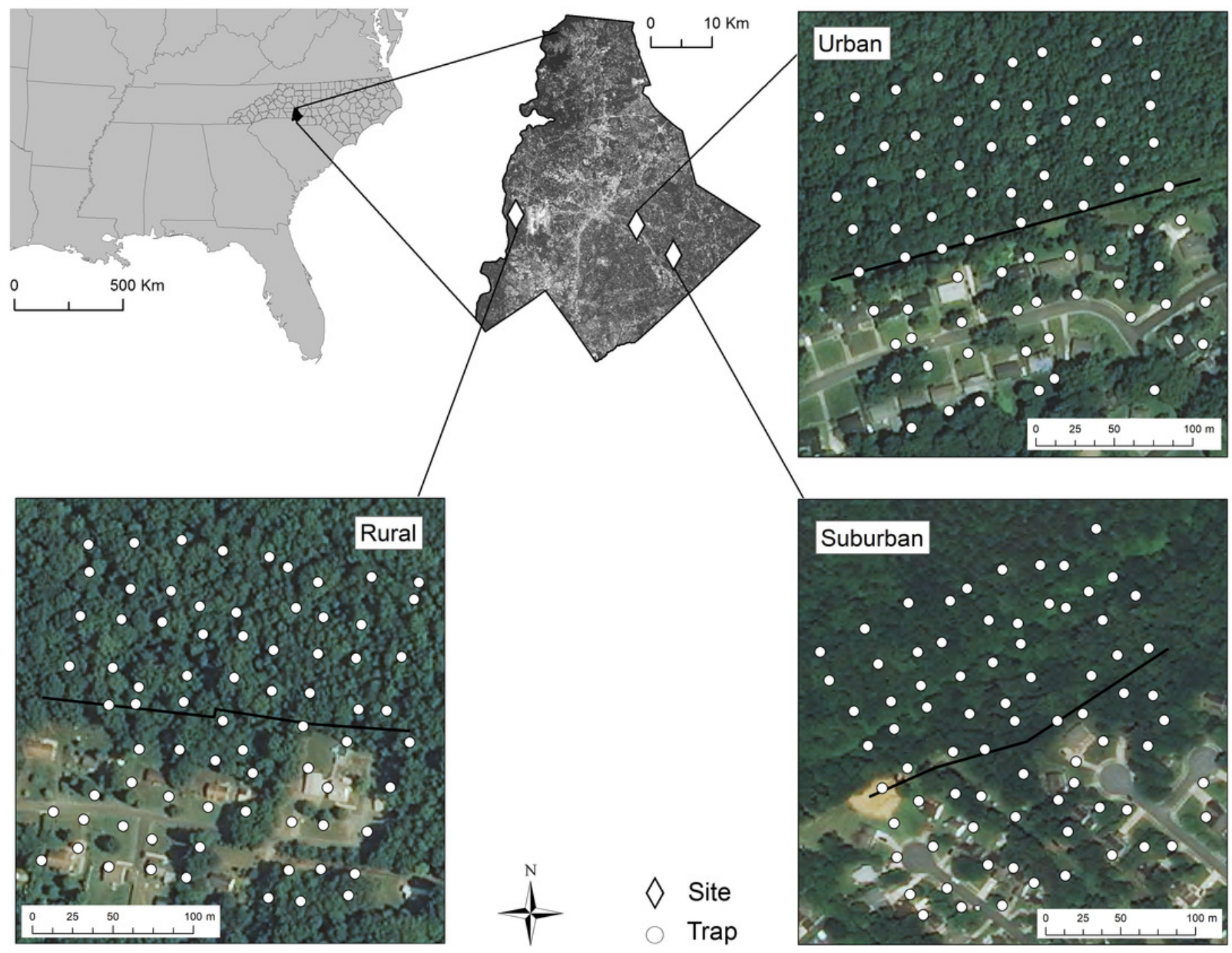




\section{Figure 2}

Boundaries at the rural site

Boundaries (yellow lines) and singletons (yellow stars) at the rural site in A) percent grass cover, B) percent canopy cover, and C) open-habitat ground beetle abundance (number of individuals per trapping period) at the small scale and in D) relative humidity, E) the BergerParker index of generalist evenness, and F) generalist abundance (number of individuals per trapping period) at the large scale. Black dots are trap locations at the small scale and the centroids of trios of adjacent trap locations at the large scale and are labeled with variable values. Edges are indicated by black lines and correspond to the property lines between County-owned forest and private development.
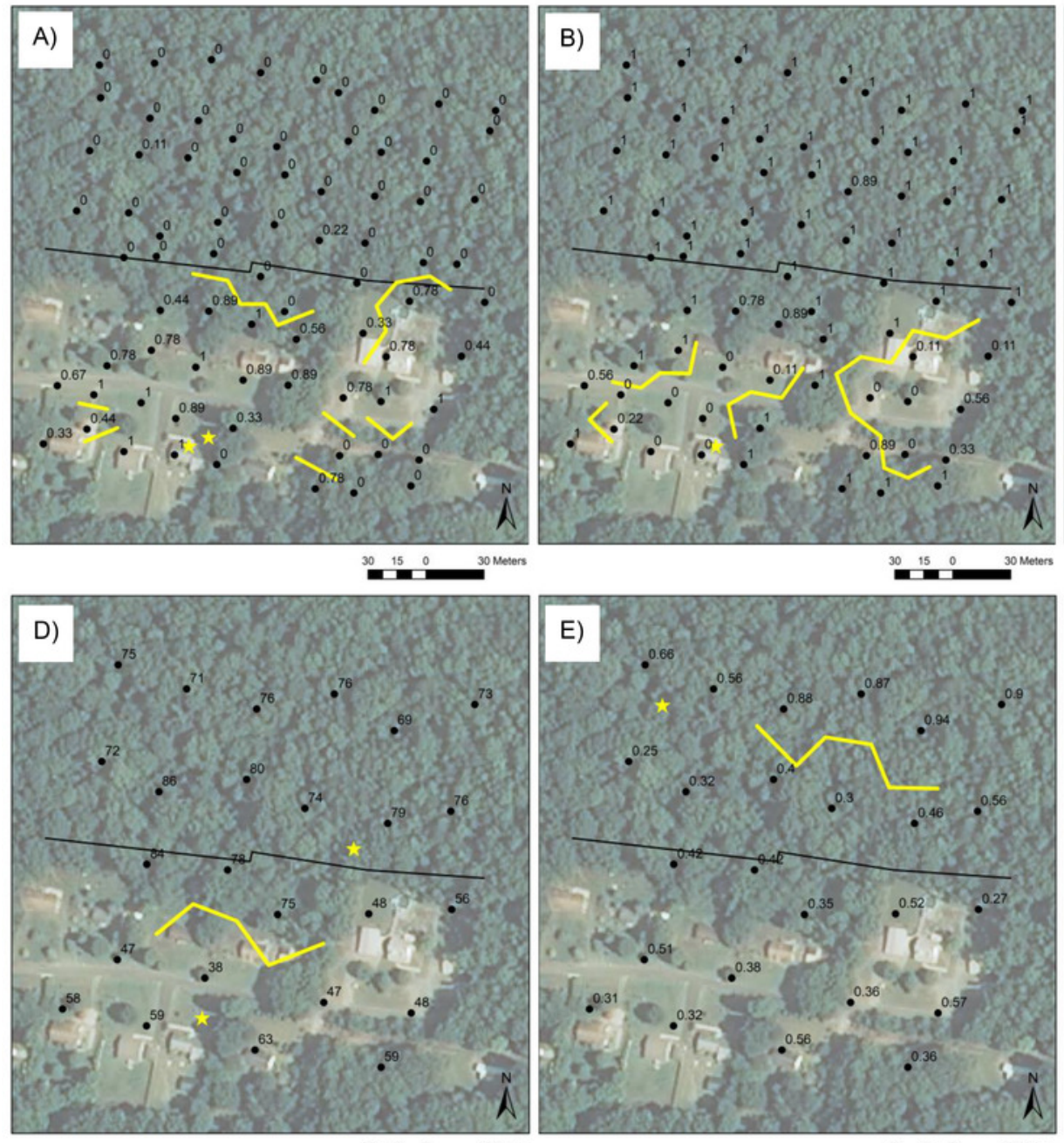

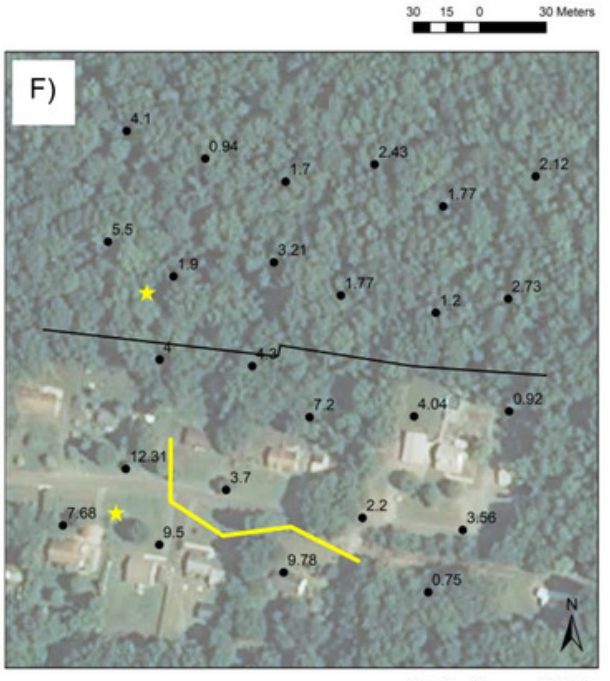




\section{Figure 3}

Boundaries at the suburban site

Boundaries (yellow lines) and singletons (yellow stars) at the suburban site in A) all environmental variables (standardized average of individual variables), B) percent forb cover, and C) Poecilus lucublandus lucublandus abundance (number of individuals per trapping period) at the small scale and in D) $P$. lucublandus lucublandus abundance (number of individuals per trapping period), E) leaf litter depth (cm), and F) total ground beetle abundance (number of individuals per trapping period) at the large scale. Black dots are trap locations at the small scale and the centroids of trios of adjacent trap locations at the large scale and are labeled with variable values. Edges are indicated by black lines and correspond to the property lines between County-owned forest and private development. 

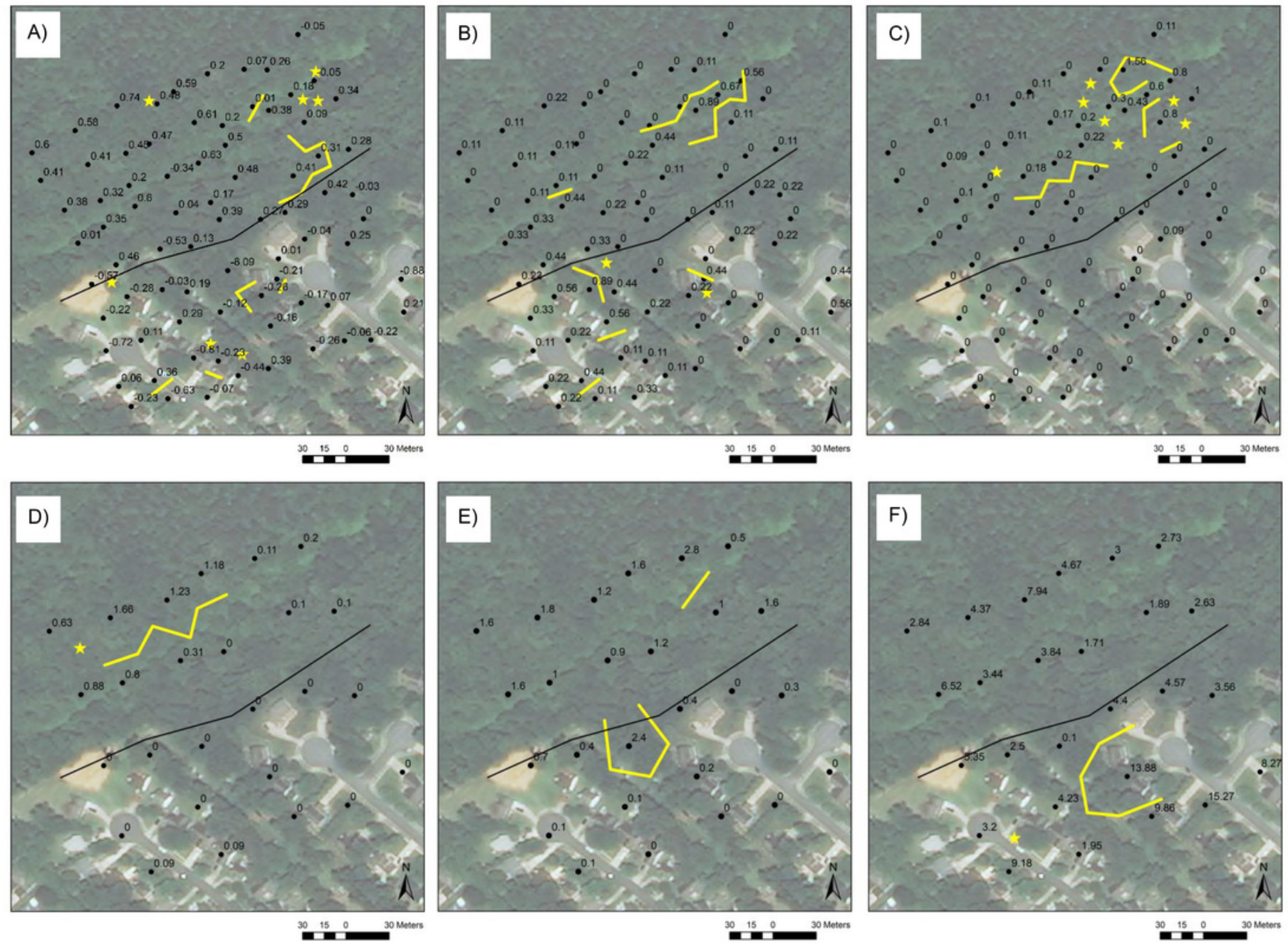


\section{Figure 4}

Boundaries at the urban site

Boundaries (yellow lines) and singletons (yellow stars) at the urban site in A) leaf litter depth (cm), B) slope index, and C) Agonum punctiforme abundance (number of individuals per trapping period) at the small scale and in D) microrelief index, E) leaf litter depth (cm), and F) generalist ground beetle richness (number of species per trapping period) at the large scale. Black dots are trap locations at the small scale and the centroids of trios of adjacent trap locations at the large scale and are labeled with variable values (missing values are indicated by -9999). Edges are indicated by black lines and correspond to the property lines between County-owned forest and private development.
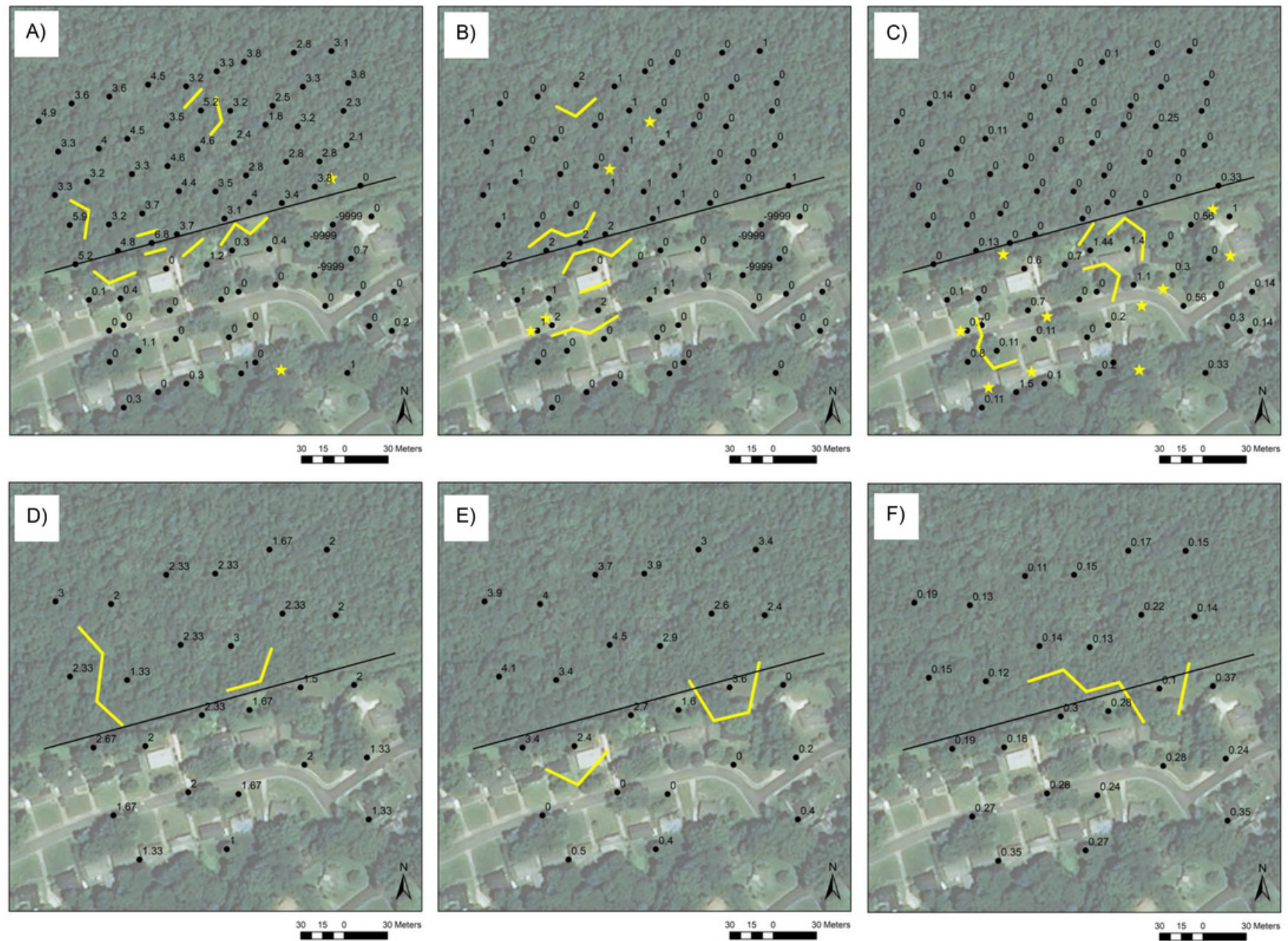


\section{Figure 5}

Clusters and boundaries

Clusters (colored dots), boundaries (yellow lines), and singletons (yellow stars) in grass cover at the rural site at the small scale (A), generalist ground beetle evenness at the rural site at the large scale (B), grass cover (C) and total evenness (D) at the suburban site at the small scale, and leaf litter depth at the urban site at the large scale (E) and at the small scale (F). Edges are indicated by black lines and correspond to the property lines between Countyowned forest and private development.
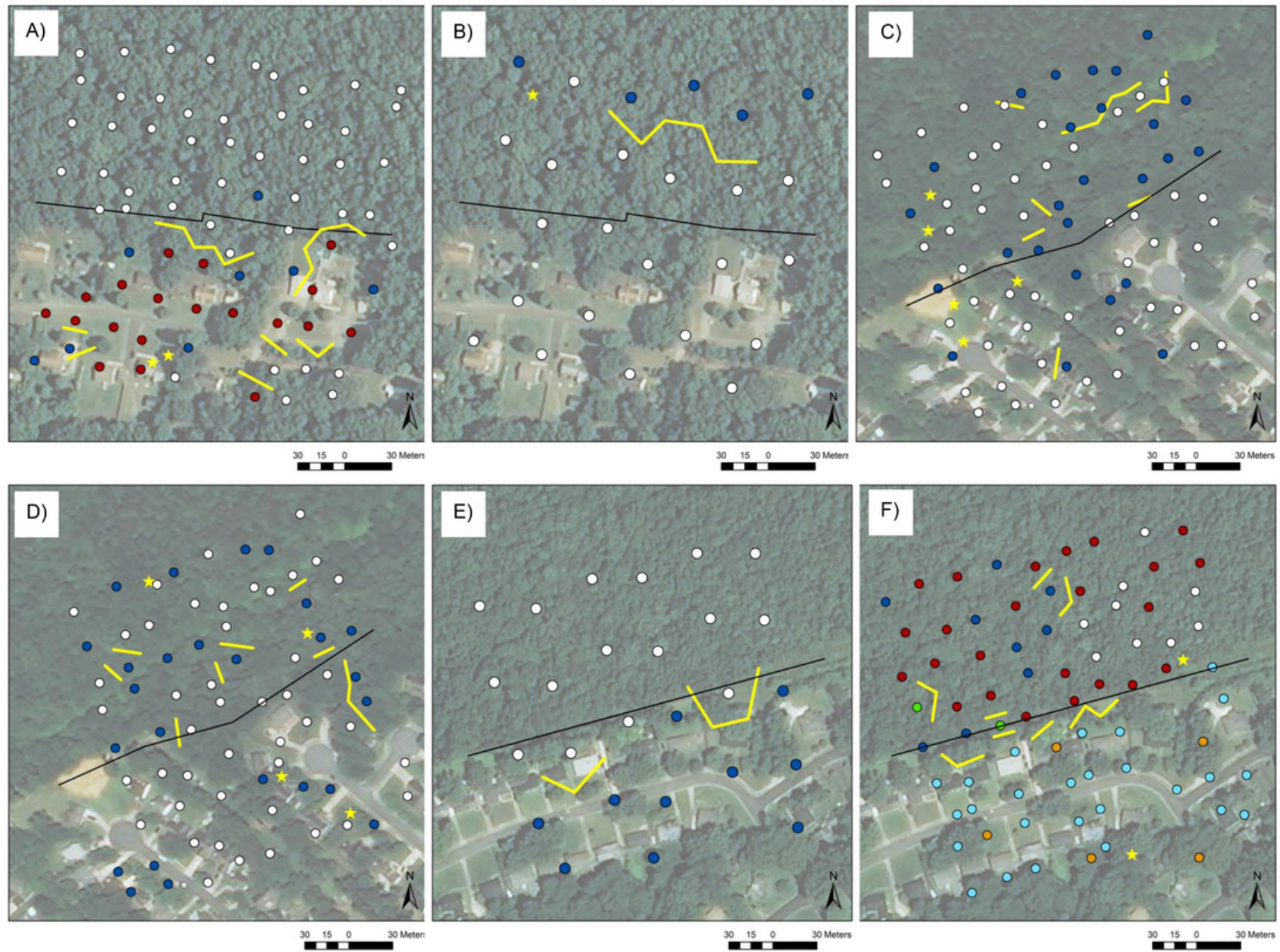